\title{
Correction to: Between Centrality and Re-scaled Identity: A New Role for the Chinese State in Shaping China's Image Abroad
}

\author{
The Case of the Twitter Account of a Chinese Diplomat in Pakistan
}

\author{
Alessandra Cappelletti ${ }^{1}$
}

(c) The Author(s) 2021

\section{Correction to: Chinese Political Science Review (2019) 4:349-374 https://doi.org/10.1007/s41111-019-00129-x}

The article "Between Centrality and Re-scaled Identity: A New Role for the Chinese State in Shaping China's Image Abroad", written by Alessandra Cappelletti was originally published Online First without Open Access. After publication in volume 4, issue 3, page 349-374 the author decided to opt for Open Choice and to make the article an Open Access publication. Therefore, the copyright of the article has been changed to (C) The Author(s) 2021 and the article is forthwith distributed under the terms of the Creative Commons Attribution 4.0 International License (https:// creativecommons.org/licenses/by/4.0/), which permits use, sharing, adaptation, distribution and reproduction in any medium or format, as long as you give appropriate credit to the original author(s) and the source, provide a link to the Creative Commons licence, and indicate if changes were made. The original article has been corrected.

The original article can be found online at https://doi.org/10.1007/s41111-019-00129-x.

Alessandra Cappelletti

Alessandra.Cap@xjtlu.edu.cn

1 Department of International Relations, Xi' an Jiaotong Liverpool University, Dushu Lake Higher Education Town, Suzhou Industrial Park, Ren'ai Road 111, Suzhou, China 